\title{
Commentary: Beware the shaggy aorta during thoracoabdominal aortic aneurysm repair!
}

\author{
Nicholas T. Kouchoukos, MD
}

\author{
From the Division of Cardiovascular and Thoracic Surgery, Missouri Baptist Medical Center, BJC Healthcare, St \\ Louis, Mo. \\ Disclosures: Author has nothing to disclose with regard to commercial support. \\ Received for publication Aug 12, 2019; revisions received Aug 12, 2019; accepted for publication Aug 12, 2019; \\ available ahead of print Sept 19, 2019. \\ Address for reprints: Nicholas T. Kouchoukos, MD, Missouri Baptist Medical Center, 3023 N Ballas Rd, Suite \\ 150D, St Louis, MO 63131 (E-mail: ntkouch@aol.com). \\ J Thorac Cardiovasc Surg 2020;160:899-900 \\ $0022-5223 / \$ 36.00$ \\ Copyright (c) 2019 by The American Association for Thoracic Surgery \\ https://doi.org/10.1016/j.jtcvs.2019.08.073
}

Extensive atherosclerosis of the thoracic and abdominal aorta (defined as "shaggy aorta" by Hollier and colleagues in 1991), ${ }^{1}$ is increasingly being recognized as a risk factor for adverse outcomes after open or endovascular repair of thoracoabdominal (TAAA) and abdominal aortic aneurysms. $^{2-5}$ In this issue of The Journal of Thoracic and Cardiovascular Surgery, Yokawa and colleagues report the outcomes of patients who underwent TAAA repair, with a focus on the subset they identified using preoperative computed tomography scanning as having "shaggy aorta." 6 Compared with patients with aortic dissection or degenerative aortic disease without extensive atheromatous changes, the patients with shaggy aorta had a significantly higher operative mortality rate and a significantly higher prevalence of spinal cord ischemic injury and acute renal failure. Femoral artery cannulation and segmental aortic clamping were important features of their operative technique. Intercostal artery implantation and cerebrospinal fluid drainage were used in a significantly lower the percentage of patients with degenerative disease compared with those with aortic dissection.

What can be done to reduce the risks associated with shaggy aorta during open repair of TAAAs? Retrograde perfusion from the femoral artery introduces the risk of embolization of atheromatous material to vital organs and, as the authors suggest, should be avoided in patients with shaggy aorta. We favor use of the axillary artery or aortic cannulation in an area free of atheroma determined using epiaortic ultrasonography in patients with extensive atheromatous disease. ${ }^{7}$ The authors also suggest that use of transesophageal echocardiography might enhance the identification of severe atheromatous disease. They have begun using intraoperative epiaortic ultrasonography to identify sites for safe aortic clamping. Routine use of these 2 diagnostic techniques should improve the accuracy of diagnosis of severe atheromatous disease, particularly of mobile atheroma.

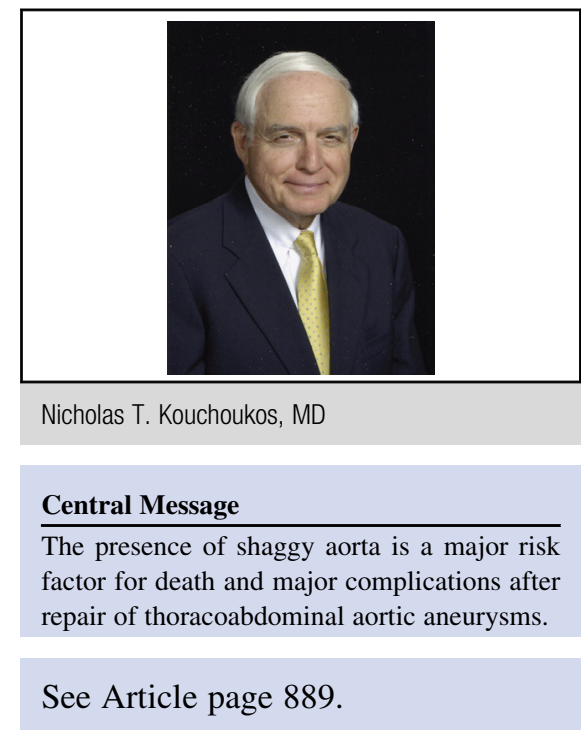

A potentially important risk factor for adverse outcomes related to thromboembolic complications in patients with extensive aortic atheroma is segmental aortic clamping. This was used extensively by the authors but was not analyzed as a potential risk factor for complications. Use of hypothermic circulatory arrest eliminates the need for segmental aortic clamping and should be considered for patients with shaggy aorta. Implantation of intercostal arteries and drainage of cerebral spinal fluid should be used when technically feasible in patients with degenerative aneurysms.

Yokawa and colleagues identified a subgroup of patients with degenerative thoracoabdominal aortic disease who are at high risk for death and serious complications after repair. ${ }^{6}$ Every intervention known to be beneficial should be applied to the identification of shaggy aorta and to the management of patients for whom it is detected.

\section{References}

1. Hollier LH, Kazier FJ, Ochsner J, Bowen JC, Procter CD. "Shaggy" aorta syndrome with atheromatous embolization to visceral vessels. Ann Vasc Surg. 1991;5:439-44.

2. Kwon H, Han Y, Noh M, Gwon JG, Cho YP, Kwon TW. Impact of shaggy aorta in patients with abdominal aortic aneurysm following open or endovascular aneurysm repair. Eur J Vasc Endovasc Surg. 2016;52:613-9.

3. Tanaka H, Minatoya K, Matsuda H, Sasaki H, Iba Y, Oda T, et al. Embolism is emerging as a major cause of spinal cord injury after descending thoracic and thoracoabdominal aortic repair with a contemporary approach; magnetic resonance findings of spinal cord injury. Interact Cardiovasc Thorac Surg. 2014;19:205-10. 
4. Okada K, Omura A, Kano H, Inoue T, Oka T, Minami H, et al. Effect of atherothrombotic aorta on outcomes of total arch replacement. J Thorac Cardiovasc Surg. 2013;145:984-91.

5. Ribeiro M, Oderich GS, Macedo T, Vrtiska TJ, Hofer J, Chini J, et al. Assessment of aortic wall thrombus predicts outcomes of endovascular repair of complex aortic aneurysms using fenestrated and branched grafts. J Vasc Surg. 2017;66:1321-33.
6. Yokawa K, Ikeno Y, Henmi S, Yamanaka K, Okada K, Okita Y. Impact of shaggy aorta on outcomes of open thoracoabdominal aortic aneurysm repair. J Thorac Cardiovasc Surg. 2020;160:889-97.e1.

7. Kulik A, Castner CF, Kouchoukos NT. Outcomes after thoracoabdominal aortic aneurysm repair with hypothermic circulatory arrest. J Thorac Cardiovasc Surg. 2011;141:953-60. 